\title{
Prevalence of physical inactivity in Saudi Arabia: a brief review
}

H.M. Al-Hazzaa'

SUMMARY Major lifestyle changes in recent years in Saudi Arabia may be leading to physical inactivity and a low level of physical fitness. This paper reviews the current literature about physical inactivity in the Saudi Arabian population and discusses its implications for health. Available data from a small number of studies suggests a high prevalence (43.3\%-99.5\%) of physical inactivity among Saudi children and adults alike. Furthermore, the proportion of Saudi children and adults who are at risk due to inactivity is much higher than for any other coronary heart disease risk factor. It is recommended that a national policy encouraging activity in daily life be established and more studies are carried out to address physical activity patterns with representative samples of the Saudi Arabian population.

\section{Introduction}

Until recent times, the physical demands of daily life and work in Saudi Arabia were sufficient to maintain a lean body mass and an appropriate level of physical fitness among the population. However, during the past 25 years, rapid developments in standards of living in the Kingdom of Saudi Arabia and increased mechanization have touched all aspects of people's lives. As a result, great changes in physical activity and eating habits have occurred in our society and low levels of physical activity and sedentary living are becoming increasingly prevalent among the Saudi population [19]. Moreover, with massive urbanization and increased reliance on computer and telecommunication technology, further reductions in physical activity are projected for the coming years.

These lifestyle changes that are rapidly occurring in Saudi Arabia (as well as in the rest of the Gulf Cooperation Council countries) have a considerable impact on the health of society. In fact, such lifestyle transformation is thought to be responsible for the epidemic of non-communicable diseases, and their complications, in this part of the world [1,10-16]. In addition, the World Health Organization (WHO) has recognized physical inactivity as a major threat to worldwide population health [17]. WHO recommended some possible goals and priority actions aimed at promoting active living. Included in these actions is the need to assess the level of physical activity among various segments of the population.

This paper aims to provide a brief overview of the published data about the level of physical activity in the Saudi Arabian population and discuss the implications of physical inactivity on the health of Saudi society. 


\section{Prevalence of physical inactivity among the Saudi Arabian population}

A MEDLINE search was made for studies published from 1990 onwards, using the words "physical activity and Saudi Arabia" and "physical inactivity and Saudi Arabia". Seven papers were found, 3 of which were relevant and were included in the review. A manual search of the local medical journals was conducted, which revealed 5 additional papers related to physical inactivity in Saudi Arabia.

That little research has been published on this important public health issue shows that research into the epidemiology of physical activity in Saudi Arabia and neighbouring countries is still in its infancy. No nationally representative population study has been made to describe the patterns of physical activity and energy expenditure of the Saudi people. The available published data on the physical activity profile of Saudi people come from studies largely conducted in urbanized areas and few of these have used large and randomized samples [2-9]. In addition, in some cases, assessment of physical activity was not the primary focus of the study $[6,8]$.

Table 1 presents a summary of physical inactivity prevalence among various segments of the Saudi population [1-9]. Seven out of the 8 reported studies used questionnaires [3-9], while 1 study involving preadolescent boys utilized continuous heart rate monitoring [2]. Across all of the studies shown in Table 1, the total rate of inactivity ranged from $43.3 \%$ to $99.5 \%$. Only 2 studies included data for both males and females and their findings indicated that females were much less active than males $[6,9]$.

Based on the results of 1 recent study involving adult men living in Riyadh city and using a fairly large and random sample, there appears to be a curvilinear relationship between inactivity prevalence and age [5]. As shown in Figure 1, the proportion of inactive men was highest during the middle-age years (30-49 years). In the same study, physical inactivity was shown to be higher among the less educated Saudi males [5]. Furthermore, the most important reasons for being physically inactive among Saudi males were time constraints and lack of facilities, as reported by more than $70 \%$ of the respondents [5]. In another study [9], the prevalence of physical inactivity in males increased from early adulthood (16-30 years) to reach its peak at a later age (46-60 years).

Overall, what is striking from the findings of these studies is that the prevalence of inactivity among the Saudi population seems to be higher than rates reported in many industrialized countries of Europe and America [18-22]. However, according to the WHO report, $60 \%$ of the world population is sedentary or not active enough to gain health benefits [17].

As shown also in Table 1, the percentage of Saudi boys who do not take moderate daily physical activity, i.e activity that raises the heart rate to above 139 beats per minute (bpm), for 30 minutes or more was reported to be $57.1 \%$ [1,2]. Such a level of moderate intensity physical activity has been recommended as a minimum level of physical activity for children and adolescents [18,23-26]. In addition, Saudi boys spend, on average, limited time on activities that raise the heart rate above $159 \mathrm{bpm}$. This level of vigorous activity is considered necessary for optimal cardiovascular health and fitness in children and adolescents [2426]. In addition, according to a recent survey conducted on a sample of adolescent boys in Riyadh city, the rate of inactive adolescents (exercising for 1 day or less per

لبحلة الصحية لشرق المتو سط، منظمة الصحة العلامية، البلملد العاشر، العدانان ع-0، ع • •؟ 


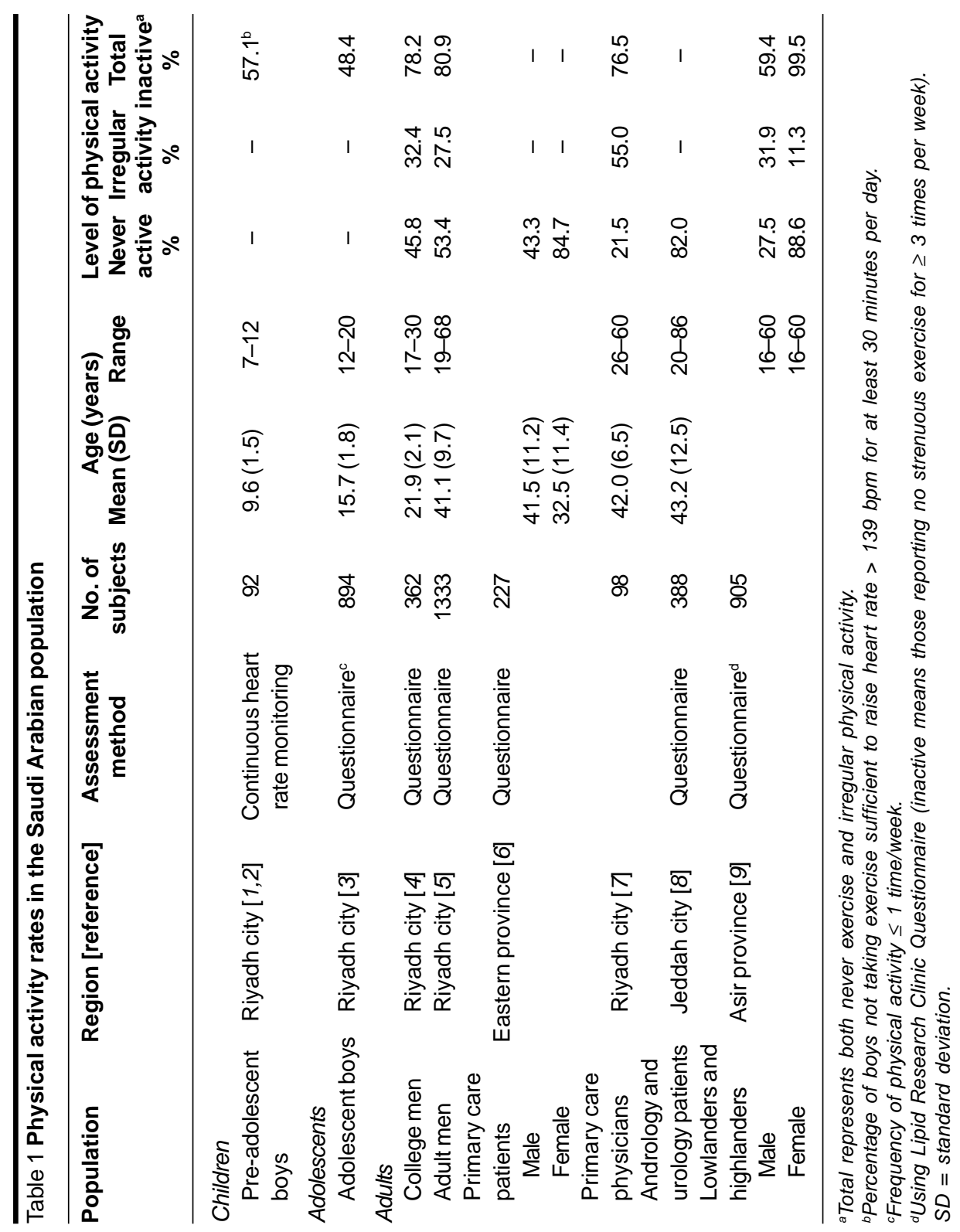

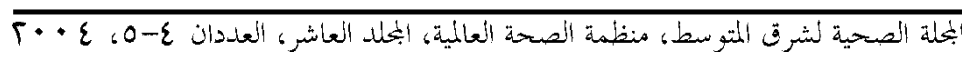




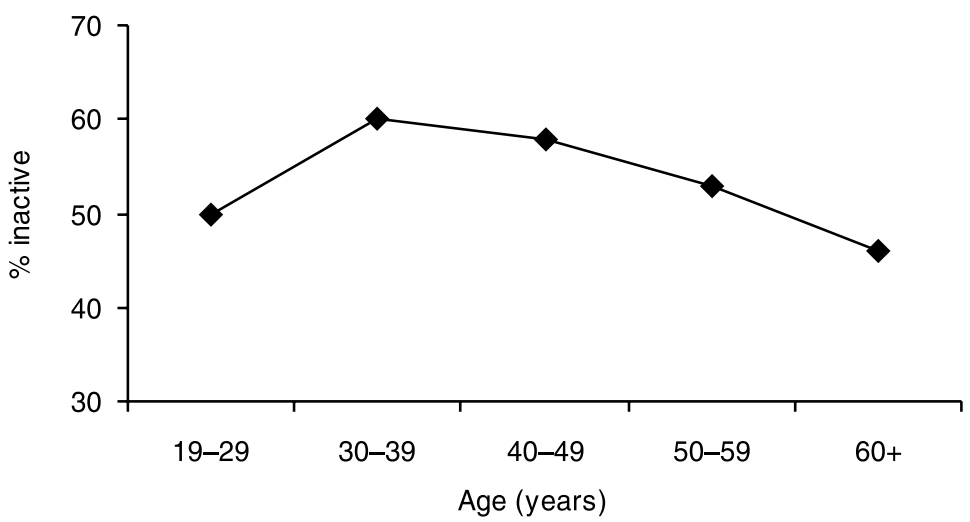

Figure 1 Prevalence of physical inactivity among Saudi Arabian males by age [5]

week) was approximate 50\% [3]. The major determinants of physical activity in Saudi children and adolescents appear to be cardiorespiratory fitness, obesity, the quality of the physical education programmes, TV viewing and parental influence [27]. From a comparative point of view, it seems that both levels of moderate (heart rate $>$ $139 \mathrm{bpm}$ ) and vigorous (> $159 \mathrm{bpm}$ ) physical activity of Saudi boys are considerably lower than those levels reported for children from other countries [19,28,29].

\section{Health implications of physical inactivity in Saudi Arabian society}

It is now well recognized that physical inactivity and increased sedentary habits represent a risk factor for a number of chronic diseases including coronary heart disease (CHD) and obesity [30,31]. On the other hand, regular physical activity has been shown to reduce the risk of both cardiovascular disease and all-cause mortality $[18,23,30,32]$. Furthermore, research on physical activity epidemiology indicates that inactivity appears to be far more im- portant risk factor than was previously estimated $[33,34]$. The reason is that there are higher proportions of the population who are inactive and at risk for CHD than those who are at risk for any of the other CHD risk factors [33,34]. Figure 2 illustrates this point using data from a recent physical activity study conducted on Saudi males [5]. The proportion of Saudi adults who are at risk due to inactivity is much higher than those at risk due to any of the other CHD risk factors, including hypertension [13], hypercholesterolaemia [14], obesity [15] and cigarette smoking [35]. Therefore, health promotion strategies aiming at decreasing the proportion of inactive Saudi adults should be a priority public health concern.

The proportion of Saudi boys who are at risk of $\mathrm{CHD}$ due to inactivity relative to other risk factors is similar to that of Saudi adults. Figure 3 clearly shows that the percentage of Saudi boys who are physically inactive is twice the rate of those with hyperlipidaemia. Diseases such as CHD and obesity, for which inactivity is a likely risk factor, have their origin in childhood [36,37]. Moreover, CHD risk factors were shown to track from childhood to adult-

بلملة الصحية لشرة المتو سط، منظمة الصحة العالمية، البحلد العاشر، العلدان ع-0، ع • • 


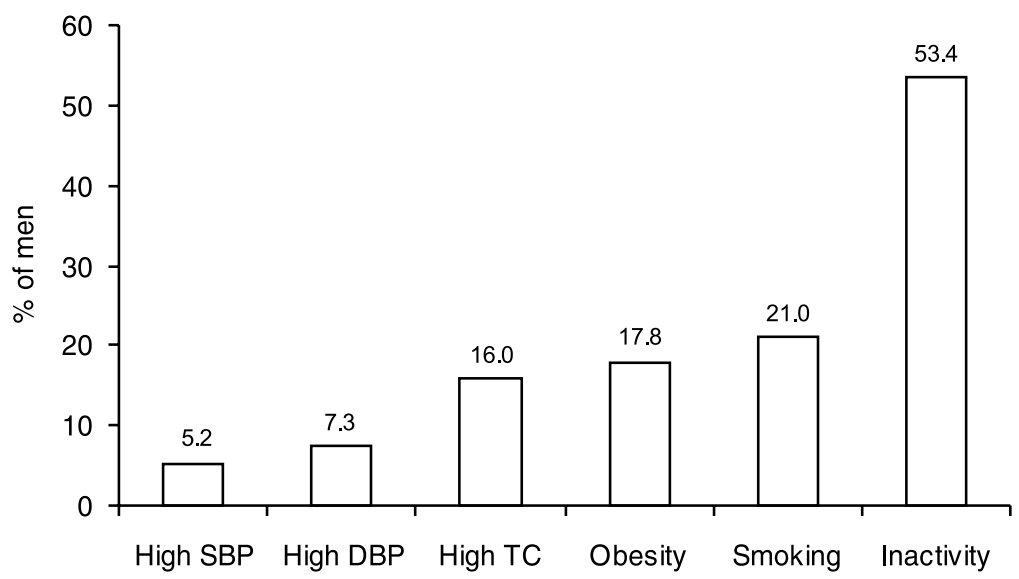

Figure 2 Risk factors for coronary heart disease among Saudi Arabian males: proportions with physical inactivity [5], high systolic (SBP) and high diastolic (DBP) blood pressure [13], high total cholesterol level (TC) [14], obesity [15] and cigarette smoking [35]

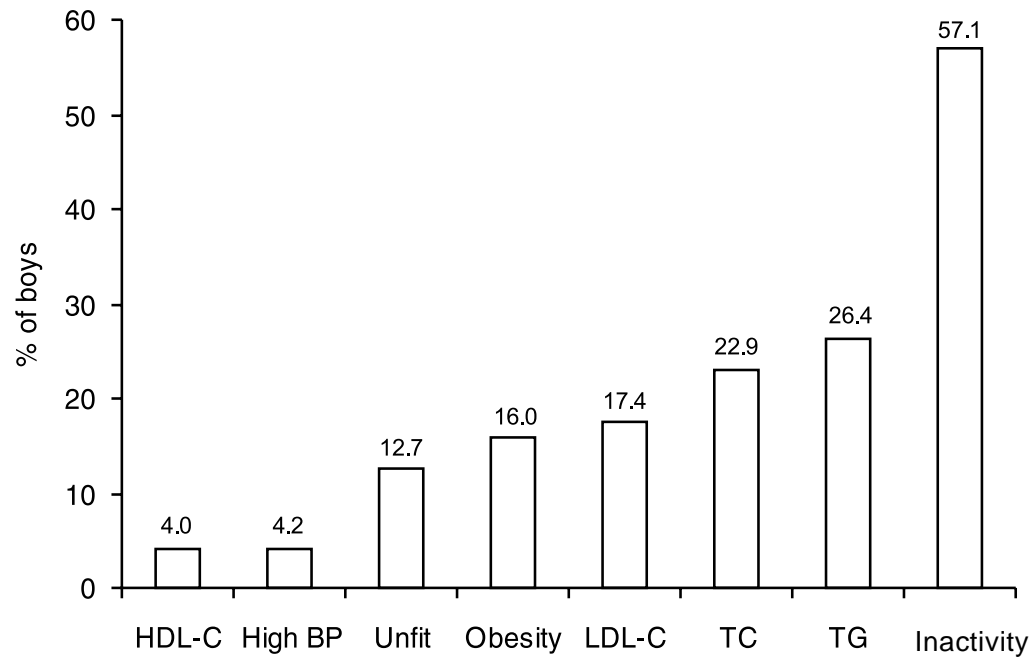

Figure 3 Risk factors for coronary heart disease among Saudi Arabian boys: proportions with physical inactivity [1,2], low high-density lipoprotein cholesterol level (HDL-C), high blood pressure (BP), low cardiorespiratory fitness (unfit), obesity (fat $>25 \%$ body mass), high lowdensity lipoprotein cholesterol level (LDL-C), high total cholesterol level (TC) and high triglycerides level (TG) [10]

لبحلة الصحية لشرق المثتوسط، منظمة الصحة العلمية، البحلد العاشر، العدذان ع-0، ع • • 
hood [38]. Thus, prevention of lifestyle-related disease at an early age is an important public health priority, especially considering the fact that children and adolescents account for more than $50 \%$ of the Saudi population. Indeed, a recent statement from the American Heart Association's Council on Cardiovascular Disease in the Young has recommended that physicians should incorporate physical activity counselling into medical practice as a way of promoting physical activity among children and adolescents [39].

\section{Conclusion and Recommendations}

From this brief review of the current level of physical activity in Saudi Arabia, it can be concluded that the prevalence of physi- cal inactivity among Saudi children, adolescents and adults is high. This may be largely the result of the recent dramatic changes in the people's lifestyle. Moreover, the proportion of Saudi children and adults who are at-risk due to inactivity is much higher than for any of the other CHD risk factors. It is recommended, therefore, that a national policy encouraging active living and discouraging inactivity be established. Such an approach has been recommended previously $[12,27]$. Health care providers have an important role in promoting physical activity and fitness among all Saudi people. Finally, national studies addressing physical activity patterns with representative samples of the Saudi population are urgently needed. Such surveillance will provide invaluable information for public health authorities and policy-makers.

\section{References}

1. Al-Hazzaa HM. Physical activity, fitness and fatness among Saudi children and adolescents: implications for cardiovascular health. Saudi medical journal, 2002, 23:144-50.

2. Al-Hazzaa HM, Sulaiman MA. Maximal oxygen uptake and daily physical activity in 7-to-12 year-old boys. Pediatric exercise science, 1993, 5:357-66.

3. Al-Rukban MO. Obesity among Saudi male adolescents in Riyadh, Saudi Arabia. Saudi medical journal, 2003, 24:27-33.

4. Al-Hazzaa HM. Physical activity profile of college male subjects. King Saud University journal, 1990, 2:383-96 [in Arabic].

5. Al-Refaee S, Al-Hazzaa HM. Physical activity profile of Saudi males: implications for health. Saudi medical journal, 2001, 22:784-9.
6. Taha AZ, Bella H. Heart disease risk factors: prevalence and knowledge in a primary care setting, Saudi Arabia. East Mediterranean health journal, 1998, 4:293-300.

7. Al-Shahri M, Al-Almaei S. Promotion of physical exercise by primary health care physicians in Riyadh city. Saudi medical journal, 1998, 19:67-9.

8. Al-Helali NS, Abolfotouh MA, Ghanem HM. Pattern of erectile dysfunction in Jeddah city. Saudi medical journal, 2001, 22:34-8.

9. Khalid M. The association between strenuous physical activity and obesity in high and low altitude populations in southern Saudi Arabia. International journal of obesity and related metabolic disorders, 1995, 19:776-80.

10. Al-Hazzaa $\mathrm{H}$ et al. Prevalence of coronary artery disease risk factors in Saudi

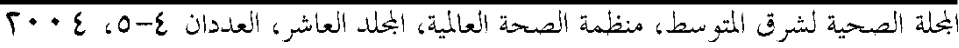


children. Journal of the Saudi Heart Association, 1993, 5:126-33.

11. Al-Hazzaa $\mathrm{H}$ et al. Cardiorespiratory fitness, physical activity patterns, and selected coronary artery disease risk factors in preadolescent boys. International journal of sports medicine, 1994, 15:267-72.

12. Alwan A. Noncommunicable diseases: a major challenge to public health in the Region. Eastern Mediterranean health journal, 1997, 3:6-16.

13. Al-Nozha M, Ali M, Osman A. Arterial hypertension in Saudi Arabia. Annals of Saudi medicine, 1997, 17:170-4.

14. Al-Nuaim A et al. Prevalence of hypercholesterolemia in Saudi Arabia, epidemiological study. International journal of cardiology, 1996, 19:41-9.

15. Al-Nuaim AR et al. High prevalence of overweight and obesity in Saudi Arabia. International journal of obesity and related metabolic disorders, 1996, 20: 547-52.

16. El-Hazmi M et al. Diabetes mellitus and impaired glucose tolerance in Saudi Arabia. Annals of Saudi medicine, 1996, $4: 381-5$.

17. Annual global Move for Health initiative: a concept paper. Geneva, World Health Organization, 2003 (WHO/NMH/PAH/ 03.1)

18. US Department of Health and Human Services. Physical activity and health: a report of the Surgeon General. Atlanta, Georgia, Centers for Disease Control and Prevention (CDC), National Centers for Chronic Disease Prevention and Health Promotion, 1996 (http:// www.cdc.gov/nccdphp/sgr/sgr.htm, accessed 26 December 2004).

19. US Department of Health and Human Services. Healthy people 2010: understanding and improving health, 2nd ed. Washington, DC, US Government Printing Office, 2000 (http://www. healthypeople.gov/Document/ tableofcontents.htm, accessed 26 December 2004).

20. Crespo CJ et al. Prevalence of physical inactivity and its relation to social class in US adults: results from the Third National Health and Nutrition Examination Survey, 1988-1994. Medicine and science in sports and exercise, 1999, 31:18217.

21. Caspersen CJ, Merritt RK. Physical activity trends among 26 states, 19861990. Medicine and science in sports and exercise, 1995, 27:713-20.

22. Caspersen C, Merritt R, Stephens T. International physical activity patterns: a methodological perspective. In: Dishman R, ed. Advances in exercise adherence. Champaign, Illinois, Human Kinetics, 1994:73-110.

23. National Institutes of Health. NIH consensus development panel on physical activity and cardiovascular health. Journal of the American Medical Association, 1996, 276:241-6.

24. American College of Sports Medicine. ACSM's guidelines for exercise testing and prescription. Baltimore, Williams and Wilkins, 2000.

25. Cavill N, Biddle S, Sallis J. Health enhancing physical activity for young people: statement of the United Kingdom expert consensus conference. Pediatric exercise science, 2001, 13:12-25.

26. Sallis J, Patrick K. Physical activity guidelines for adolescents: consensus statement. Pediatric exercise science, 1994, 6:302-14.

27. Al-Hazzaa H. Patterns of physical activity among Saudi children, adolescents and adults with special reference to health. In: Musaiger A, Miladi S, eds. Nutrition

لبحلة الصحية لشرق المثتوسط، منظمة الصحة العلمية، البحلد العاشر، العدذان ع-0، ع • • 
and physical activity in the Arab countries of the Near East. Manama, Bahrain Centre for Studies and Research, 2000: 109-27.

28. Armstrong N, Bray S. Physical activity patterns defined by continuous heart rate monitoring. Archives of disease in childhood, 1991, 66:245-7.

29. Sallo M, Silla R. Physical activity with moderate to vigorous intensity in preschool and first grade schoolchildren. Pediatric exercise science, 1997, 9:4454.

30. Leon A, ed. Physical activity and cardiovascular health. A national consensus. Champaign, Illinois, Human Kinetics, 1997.

31. Bijnen FC, Caspersen CJ, Mostard WL. Physical inactivity as a risk factor for coronary heart disease: a WHO and International Society and Federation of Cardiology position statement. Bulletin of the World Health Organization, 1994, 72(1):1-4.

32. Blair SN et al. Physical fitness and allcause mortality: a prospective study of healthy men and women. Journal of the American Medical Association, 1989, 262:2395-401.

33. Caspersen CJ. Physical activity epidemiology: concepts, methods and applications to exercise science. Exercise and sport sciences reviews, 1989, 17: 423-73.
34. Powell K. Population attributable risk of physical inactivity. In: Leon A, ed. Physical activity and cardiovascular health. A national consensus. Champaign, Illinois: Human Kinetics, 1997:40-7.

35. Jarallah JS et al. Prevalence and determinants of smoking in three regions of Saudi Arabia. Tobacco control, 1999, 8:53-6.

36. Berenson $\mathrm{G}$ et al. Association between multiple cardiovascular risk factors and atherosclerosis in children and young adults. The Bogalusa Heart Study. New England journal of medicine, 1998, 338(23):1650-6.

37. McGill HC Jr et al. Association of coronary heart disease risk factors with microscopic qualities of coronary atherosclerosis in youth. Circulation, 2000, 102:374-9.

38. Webber LS et al. Tracking of serum lipids and lipoproteins from childhood to adulthood. The Bogalusa Heart Study. American journal of epidemiology, 1991, 133: 884-99.

39. Williams $C$ et al. Cardiovascular health in childhood. A statement for health professionals from the committee on atherosclerosis, hypertension, and obesity in the young (AHOY) of the council on cardiovascular disease in the young, American Heart Association. Circulation, 2002, 106:143-60. 